\title{
Deep vein thrombosis and bilateral pulmonary embolism following minor trauma to the popliteal fossa: could this have been avoided?
}

\author{
Jason Orlik, BSc, MD*; Jennifer McVey, BSc, MSc, MD ${ }^{\dagger}$
}

\begin{abstract}
Deep vein thrombosis (DVT) with subsequent pulmonary embolus (PE) is frequently fatal if untreated. Athletes may be susceptible to DVT following minor blunt trauma to the popliteal fossa. We report an adult male hockey player with no "classic" risk factors for DVT who presented with a DVT and bilateral PE following minor popliteal blunt trauma. This case report illustrates the utility of likelihood ratios when interpreting the results of diagnostic tests such as Doppler ultrasonography.
\end{abstract}

\section{RÉSUMÉ}

La thrombose veineuse profonde (TVP) suivie d'une embolie pulmonaire (PE) est souvent mortelle si elle n'est pas traitée. Les athlètes peuvent être sensibles à la TVP après un traumatisme fermé mineur du creux poplité. Nous décrivons le cas d'un joueur de hockey adulte ne présentant aucun facteur de risque "classique " de TVP, mais ayant une TVP et une EP bilatérale consécutives à un traumatisme fermé du creux poplité. Ce rapport de cas illustre I'utilité des rapports de vraisemblance lors de l'interprétation des résultats de tests diagnostiques tels que l'échographie Doppler.

Keywords: deep vein thrombosis, likelihood ratio, minor trauma, popliteal fossa, pulmonary embolism

Presentation of patients to emergency departments (EDs) with symptoms and signs suggestive of deep vein thrombosis (DVT) is common. DVT has an incidence of 66 per 100,000 per year, ${ }^{1}$ and DVTs commonly occur in the popliteal and femoral veins. ${ }^{2}$ From these sites, thrombi may embolize to the lungs. Pulmonary embolism (PE) will develop in approximately $50 \%$ of untreated DVT's, many of which will be asymptomatic. $^{3}$ PEs are potentially fatal; 35\% of patients will die if left untreated or the PE is undetected, and $5 \%$ of patients will die even with appropriate treatment. ${ }^{3}$ It is vitally important to accurately diagnose DVT and promptly initiate treatment to reduce the risks of patients' developing a PE. As the symptoms of DVT are nonspecific, ${ }^{4}$ investigation of DVT is dependent on physicians' having a high index of clinical suspicion. Pretest probability (PTP) for DVT can be based on gestalt or clinical decision aids; the Wells criteria are a sensible, reliable, and valid tool developed and used widely in Canada. ${ }^{5}$ After determining PTP, further investigative decisions are dictated by the low, moderate, or high PTP status of each patient.

The following case describes a patient with a DVT and subsequent PE following minor trauma to the popliteal area, ${ }^{6}$ with a discussion of how to proceed following ambiguous test results. The case illustrates how PTPs may be used to guide interpretation of test results in conjunction with positive and negative likelihood ratios (LRs) and, therefore, subsequent patient management.

\section{CASE REPORT}

A 37-year-old male presented to the ED with pain and swelling to the left calf. He had been hit in the popliteal fossa with a hard plastic ball while playing ball hockey 10 days previously. His past medical history was significant only for myocardial infarction 3 years previously, for which he underwent coronary

From the *UBC Okanagan Family Medicine Program, Kelowna, BC; and tDepartment of Emergency Medicine, Dalhousie University, Halifax, NS.

Correspondence to: Dr. Jason Orlik, Family Medicine Residency Office, 2268 Pandosy Street, Kelowna, BC V1Y 1T2; jorlik@dal.ca.

Submitted October 19, 2010; Revised NA; Accepted November 24, 2010

This article has been peer reviewed. 
stent placement. The patient had no other known risk factors for DVT or PE (specifically no history of smoking, malignancy, recent long trips, surgery, or immobilization, and there was no family history of clotting disorders). Also of note, there was no period of relative immobility following his injury. His only medication was rosuvastatin. On physical examination, he looked well and his vital signs were normal. He denied any shortness of breath or chest pain. His only complaint and physical examination finding were swelling and pain in the left upper calf, which was $5 \mathrm{~cm}$ greater than the right. There was also pitting edema and whole leg swelling.

Laboratory investigations included a positive Ddimer $(287 \mathrm{ng} / \mathrm{mL})$; his international normalized ratio (INR) was 1.2, and his partial thromboplastin time (PTT) was 54 seconds. A Doppler sonogram was positive for DVT with thrombus located in the posterior tibial veins, and the patient was placed on 18,000 units of dalteparin. A follow-up Hematology consultation was arranged for the next day, and repeat ultrasonography (US) performed then revealed no DVT but, rather, a thrombus in the small saphenous vein (also known as the short, or lesser, saphenous vein), which was superficial. The decision was made by the hematologist to discontinue anticoagulant therapy. The rationale was that it would be unlikely that the thrombus would extend because it had been present for approximately 10 to 12 days. The patient was placed on naproxen for his symptoms.

Nine days later, a repeat sonogram demonstrated that the clot had extended into the proximal popliteal vein. The patient was again placed on dalteparin and warfarin. After 5 days, dalteparin was discontinued and warfarin was maintained as his INR was therapeutic.

Seven days later, the patient woke up with intense midthoracic back and chest pain described as pleuritic in nature. On returning to the ED, he denied any shortness of breath, fever, cough, or hemoptysis. His vital signs were normal, he appeared well, and his physical examination was unremarkable; however, his PTP for PE was high (Table 1). His INR was 3.3. Spiral computed tomography revealed bilateral PE. The patient was briefly treated with intravenous heparin and then discharged home on warfarin, with no further adverse events. Of note, follow-up investigations for thrombophilia were negative, including antithrombin III deficiency, factor V Leiden, anticardiolipin, antinuclear antibody, anti-DNA, and lupus anticoagulant.

$\begin{aligned} & \text { Table 1. Wells rule for predicting pretest probability of } \\ & \text { pulmonary embolism }\end{aligned}$
$\begin{aligned} & \text { Clinical characteristic } \\ & \text { Previous pulmonary embolism } \\ & \quad \text { or deep vein thrombosis }\end{aligned}$
$\begin{aligned} & \text { Heart rate }>100 \text { beats per } \\ & \text { minute }\end{aligned}$
$\begin{aligned} & \text { Recent surgery or } \\ & \text { immobilization }\end{aligned}$
$\begin{aligned} & \text { Clinical signs of deep vein } \\ & \text { thrombosis }\end{aligned}$
$\begin{aligned} & \text { Alternative diagnosis less likely } \\ & \text { than pulmonary embolism }\end{aligned}$
$\begin{aligned} & \text { Hemoptysis } \\ & \text { Cancer }\end{aligned}$
$\begin{aligned} & \text { Clinical probability of pulmonary embolism; low }=0-1 \text {; intermediate }=2-6 ; \text { high }=\text { greater } \\ & \text { than } 7 .{ }^{4}\end{aligned}$

\section{DISCUSSION}

Could the extension of DVT to a PE been avoided in this case? Following his primary presentation to the $\mathrm{ED}$, a repeat diagnostic test (US) was obtained for this patient. The results contradicted earlier findings and culminated in a change in management without meaningful interpretation of a previously positive sonogram. This issue is discussed in detail below.

This patient had no classic risk factors for DVT (Table 2); however, using the established clinical criteria for DVT probability of Wells and colleagues, ${ }^{7}$ his score was 3 (e.g., entire leg swelling, localized

\begin{tabular}{|c|c|}
\hline Risk factor & Patients (\%) \\
\hline Age $>40 y r$ & 88.5 \\
\hline Obesity & 37.8 \\
\hline $\begin{array}{l}\text { History of venous } \\
\text { thromboembolism }\end{array}$ & 26.0 \\
\hline Cancer & 22.3 \\
\hline Bed rest $>5 d$ & 12.0 \\
\hline Major surgery & 11.2 \\
\hline Congestive heart failure & 8.2 \\
\hline Varicose veins & 5.8 \\
\hline Fracture (hip or leg) & 3.7 \\
\hline Estrogen treatment & 2.0 \\
\hline Stroke & 1.8 \\
\hline Multiple trauma & 1.1 \\
\hline Childbirth & 1.1 \\
\hline Myocardial infarction & 0.7 \\
\hline
\end{tabular}


tenderness along the distribution of the deep venous system, and calf swelling $>3 \mathrm{~cm}$ larger than asymptomatic side). As per the Wells criteria, the PTP of DVT was high (Table 3). With a high PTP, the prevalence of DVT is approximately $53 \%$ (95\% CI 44-61). ${ }^{7}$ In other words, there is a $53 \%$ chance that this patient has a DVT, or about the same as flipping a coin.

A valuable diagnostic test is performed to shift this PTP of disease to a higher or lower posttest probability. In this sense, it is useful to consider LRs when interpreting test results ${ }^{8}$ as this ultimately affects management decisions. The LRs are derived from the sensitivities and specificities of a given test.

In this case, the appropriate first diagnostic test was Doppler US. Although a D-dimer may be used in low and moderate test circumstances, Doppler US has reported sensitivity of 0.89 (95\% CI $0.88-0.90)$ and specificity of 0.94 (95\% CI $0.93-0.94) .{ }^{9}$ Therefore, calculations of LRs are as follows: $+\mathrm{LR}=$ sensitivity $/ 1$ - specificity $=14.8-\mathrm{LR}=1-$ sensitivity/specificity $=0.12$.

A test with $a+L R>10$ is considered useful for ruling in a given condition with a moderate PTP. ${ }^{8}$ Conversely, a test with a $-\mathrm{LR}<0.10$ would be considered useful for ruling out the same condition in a similar group. ${ }^{8}$ The Doppler US therefore meets the psychometric properties of a valuable diagnostic test. These data are then applied on a Fagan nomogram, ${ }^{10}$ as shown in Figure 1. Using this figure, we can see that given that our patient had a PTP for DVT of $53 \%$, the posttest probability is increased to over $90 \%$ with the positive sonogram. Even a negative initial sonogram would have reduced the posttest probability only to approximately $12 \%$ and would mandate further investigative strategies (ie, other testing or repeat US in 1 week). Although it is important that US be repeated to detect missed DVT's in high-probability patients, ${ }^{7,11}$ a repeat sonogram that is negative after an initial positive sonogram will not change the pretest probability. Thus, the results from the second sonogram mean that the patient still had at least a $12 \%$ chance of DVT, which would warrant further investigation. That being said, in the setting of an initially positive sonogram, one could argue that the PTP was even higher before the second sonogram.

Of interest, this report also highlights the need for serial US in the case of a suspected calf vein DVT. If a below knee ("calf vein") DVT was suspected, treatment with nonsteroidal antiinflammatory agents would be appropriate assuming that serial US tests were available to detect the progression of clot into more proximal deep veins. Although rare, this progression is an important finding, one that emergency physicians should suspect.

In our case, when the second sonogram was reported as negative, this posed a diagnostic dilemma influencing the decision to continue anticoagulation. This is

\begin{tabular}{|c|c|}
\hline Clinical characteristic & Score \\
\hline $\begin{array}{l}\text { Active cancer (treatment ongoing, administered } \\
\text { within previous } 6 \mathrm{mo} \text {, or palliative) }\end{array}$ & 1 \\
\hline $\begin{array}{l}\text { Paralysis or paresis or recent plaster } \\
\text { immobilization of the lower extremities }\end{array}$ & 1 \\
\hline $\begin{array}{l}\text { Recently bedridden }>3 \mathrm{~d} \text { or major surgery within } \\
\text { previous } 12 \mathrm{wk} \text { requiring general or local } \\
\text { anesthesia }\end{array}$ & 1 \\
\hline $\begin{array}{l}\text { Localized tenderness along distribution of the } \\
\text { deep venous system }\end{array}$ & 1 \\
\hline Swelling of entire leg & 1 \\
\hline $\begin{array}{l}\text { Calf swelling }>3 \mathrm{~cm} \text { larger than asymptomatic } \\
\text { side (measured } 10 \mathrm{~cm} \text { below tibial tuberosity) }\end{array}$ & 1 \\
\hline Pitting edema confined to the symptomatic leg & 1 \\
\hline Collateral superficial veins (nonvaricose) & 1 \\
\hline Previously documented DVT & 1 \\
\hline Alternative diagnosis at least as likely as DVT & -2 \\
\hline
\end{tabular}




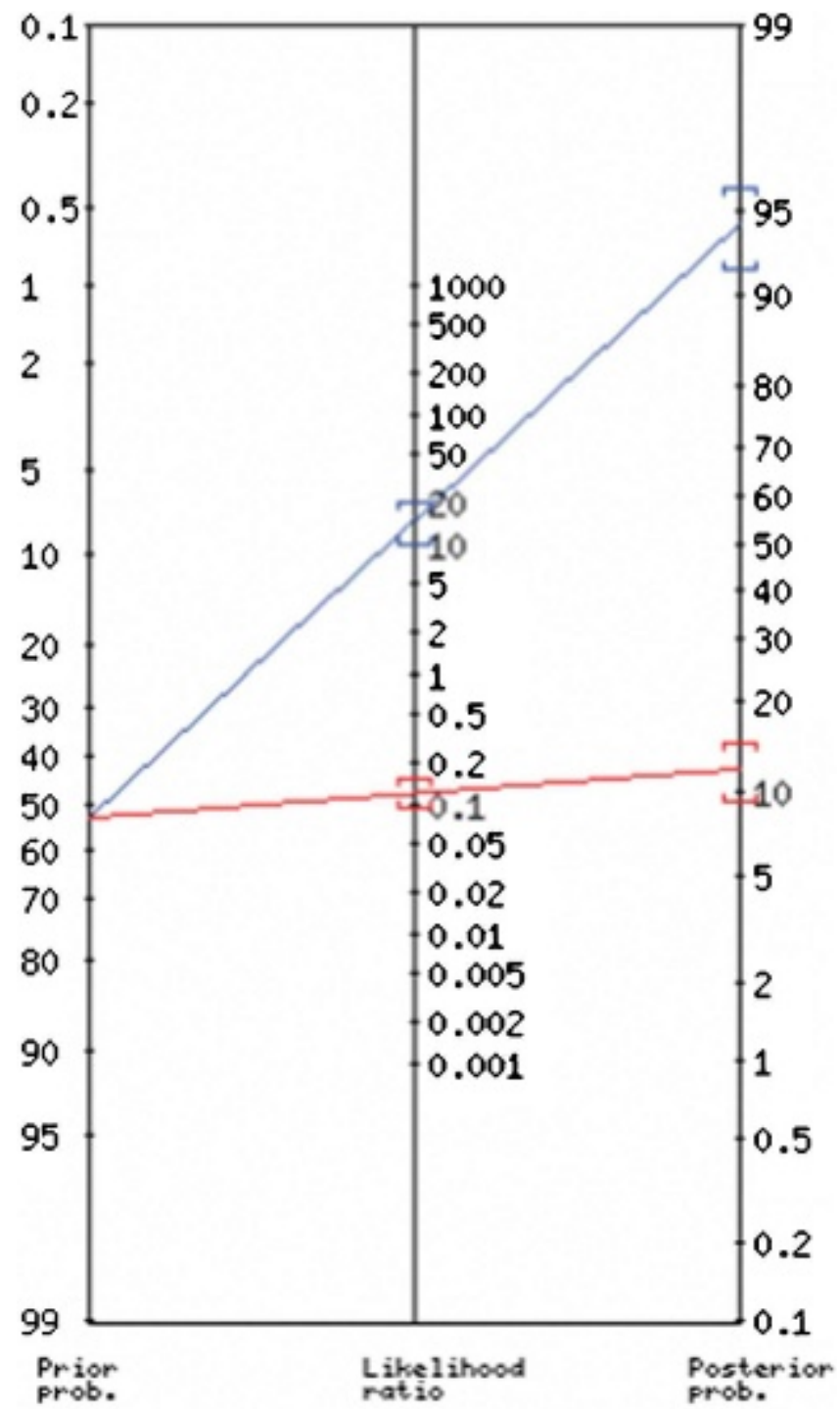

Figure 1. Nomogram: likelihood ratios of deep vein thrombosis with high pretest probability and ultrasound testing. Previous probability (OR) $53 \%$ (1.1). Positive test: positive likelihood ratio $15,95 \% \mathrm{Cl} 10-21$; posterior probability (OR) 94\% (16.9), 95\% Cl 92-96. Negative test: negative likelihood ratio $0.12 ; 95 \% \mathrm{Cl} 0.09-0.15$; posterior probability (OR) $12 \%$ (0.1), 95\% Cl 9-14. Adapted from Schwartz A. ${ }^{10}$

an excellent example of how LRs may be used to guide the interpretation of test results and therefore management decisions. Fortunately, the patient underwent a third sonogram that again was positive, and the decision was made to restart anticoagulation.

In terms of the discrepancy between the two US reports, this could have been due to interrater reliability; however, it has been shown that with experienced observers, interobserver reliability for lower extremity DVT is excellent, at $94 \% .{ }^{12}$ It is unclear why the second sonogram was negative; however, it does not change the fact that there was a previous positive sonogram. This patient had a posttest probability of DVT greater than $90 \%$ after the initial positive sonogram, suggesting that he should have been maintained on the appropriate dose and duration of anticoagulant therapy. Confirmation of venous thromboembolism is a critically important issue for all physicians and patients; discordant test results should mandate a more vigorous search for the truth. Despite resuming anticoagulant therapy and demonstrating therapeutic INRs, this patient experienced a subsequent $\mathrm{PE}$, illustrating that PEs are a risk in patients with DVTs even when receiving appropriate therapy. As heparin accelerates clot removal over 48 to 72 hours by allowing unopposed action of plasmin, this patient was started on intravenous heparin and maintained on oral anticoagulation without further complication. ${ }^{13}$

\section{CONCLUSION}

This case report of DVT and bilateral PE provides an excellent illustration of the utility of PTP and LRs for interpreting diagnostic test results. It also demonstrates the potential impact that this may have on subsequent management decisions and patient outcomes.

Competing interests: None declared.

\section{REFERENCES}

1. White RH. The epidemiology of venous thromboembolism. Circulation 2003;107(23 Suppl):I4-8.

2. Scarvelis D, Wells PS. Diagnosis and treatment of deep-vein thrombosis. CMA7 2006;175:1087-92.

3. Kearon C. Natural history of venous thromboembolism. Circulation 2003;107(23 Suppl):I22-30.

4. Fox JC, Otarodifard K, Deavers M. Diagnostic and therapeutic keys to deep vein thrombosis. Emerg Med 2006;38:14-20.

5. Anderson DR, Wells PS, Stiell I, et al. Thrombosis in the emergency department: use of a clinical diagnosis model to safely avoid the need for urgent radiological investigation. Arch Intern Med 1999;159:477-82.

6. Echlin PS, Upshur REG, McKeag DB, et al. Traumatic deep vein thrombosis in a soccer player: a case study. Thromb 7 2004;2:1-5.

7. Wells PS, Owen C, Doucette S, et al. Does this patient have deep vein thrombosis? 7AMA 2006;295:199-207.

8. Jaeschke R, Guyatt GH, Sackett DL. Users' guides to the medical literature III. How to use an article about a diagnostic test $\mathrm{B}$. What are the results and will they help me care for my patients? JAMA 1994;271:703-7.

9. Goodacre S, Sampson F, Thomas S, et al. Systematic review and meta-analysis of the diagnostic accuracy of 
ultrasonography for deep vein thrombosis. BMC Med Imaging 2005;5:6.

10. Schwartz A. Diagnostic test calculator. 2007. Available at: araw. mede.uic.edu/cgi-bin/testcalc.pl (accessed Feb 21, 2011).

11. Heijboer H, Buller HR, Lensing A, et al. A comparison of real-time compression ultrasonography with impedance plethysmography for the diagnosis of deep vein thrombosis in symptomatic outpatients. N Engl f Med 1993;329: 1365-9.

12. Schwartz T, Schmidt B, Schmidt B, et al. Interobserver agreement of complete compression ultrasound for clinically suspected deep vein thrombosis. Clin Appl Thromb Hemost 2002;8:45-9.

13. Hull RD, Raskob GE, Brant RF, et al. Relation between the time to achieve the lower limit of the APTT therapeutic range and recurrent venous thromboembolism during heparin treatment for deep vein thrombosis. Arch Intern Med 1997;157:2562-8.

14. Chagnon I, Bounameux H, Aujesky D, et al. Comparison of two clinical prediction rules and implicit among patients with suspected pulmonary embolism. Am 7 Med 2002;113:269-75.

15. Anderson FA, Spencer FA. Risk factors for venous thromboembolism. Circulation 2003;107(23 Suppl):I9-16. 